\title{
SEXUAL ORIENTATION AND SOCIAL ATTITUDES
}

\author{
Landon Schnabel ${ }^{*}$ \\ Indiana University, Bloomington
}

\begin{abstract}
Gender, race, and class strongly predict social attitudes and are at the core of social scientific theory and empirical analysis. Sexuality (i.e., sexual orientation), however, is not as central a factor by which we conceptualize and systematize society. This study examines the impact of sexual orientation, gender, race, and education across attitudinal topics covered by the General Social Survey. Sexual orientation is an important part of people's lives that, as I demonstrate, is a strong and exceptionally consistent predictor of social attitudes across issues regardless of whether it is measured with partnering behavior or self-identification. When sexual behavior and identity differ, however, identity is more influential. This pattern lends support to a marginalized identity explanation for why sexual minorities are consistently liberal. I conclude that future work should pay more attention to sexuality as a core factor in social scientific theory and empirical analysis.
\end{abstract}

Keywords: Sexual Orientation; Public Opinion; Attitudes; Identity; Sexuality; Gender; Race; Class; Education

Last Revised: 2018-03-06

Words: 10,256

Figures: 4

Tables: 5

\section{THIS PAPER IS FORTHCOMING IN SOCIUS}

\footnotetext{
* The author is indebted to Brian Powell for exceptional support and feedback on this project. He would also like to thank Kristin Kelley for independently replicating key results. This project was presented and benefited from comments at the 2016 meetings of the American Association for Public Opinion Research. The author received financial support from Indiana University's John H. Edwards Fellowship while working on this project. Direct correspondence to Landon Schnabel, Department of Sociology, Indiana University, 744 Ballantine Hall, 1020 E. Kirkwood Ave., Bloomington, IN 47405. Email: lpschnab@indiana.edu.
} 
Gender, race, and class strongly predict social attitudes and are core factors of social scientific research, especially in the study of public opinion and politics (Bobo and Hutchings 1996; Hutchings and Valentino 2004; Page and Shapiro 1992; Strolovitch 2008). These sociodemographic characteristics linked to personal experiences, social status, and shared group identities and interests shape how people approach social and political life (Brooks and Manza 1997; Collins 2000; Jackman 1994; Longest, Hitlin, and Vaisey 2013; Sniderman and Piazza 2002). In many but not all domains women are more liberal than men, Blacks more liberal than whites, and college graduates more liberal than those with less education (Box-Steffensmeier, DeBoef, and Lin 2004; Freese, Powell, and Steelman 1999; Schnabel 2016a; Schuman et al. 1997). Beyond their importance for predicting public opinion and politics, gender, race, and class are key axes by which social scientists systematize society. In this study, I offer evidence for the inclusion of sexuality (i.e., sexual orientation) with these core sociodemographic factors in at least attitudinal research.

A large and rapidly growing body of literature examines sexual minorities as social objects (i.e., attitudes toward them) (Adamczyk 2017; Baunach 2012; Doan, Loehr, and Miller 2014; Powell et al. 2010; Powell, Schnabel, and Apgar 2017; Schnabel and Sevell 2017; Sherkat et al. 2011), but less research has examined sexual minorities as social subjects (i.e., their attitudes). Scholars have increasingly explored how sexuality relates to religion (Sherkat 2002; Yip and Page 2013) and voting behavior (Egan 2012; Hertzog 1996; Lewis, Rogers, and Sherrill 2011; Mucciaroni 2011; Schaffner and Senic 2006), but only a handful of studies have examined sexuality and social attitudes (Egan and Sherrill 2005; Sherrill 1996; Worthen, Sharp, and Rodgers 2012). The few available studies typically have used non-representative data and/or examined a limited number of attitudes. Only a systematic, broad, and nationally-representative 
study of sexuality and public opinion can answer all of the following questions: Is sexuality a significant sociodemographic divide that shapes sociopolitical attitudes? Is it a consistent factor across an extensive range of attitudinal items? More broadly, does sexuality matter enough to be a central and maybe even standard factor by which we conceptualize and systematize society?

To answer these questions, this study examines the impact of sexual orientationmeasured by partnering behavior and by self-identification — and other key sociodemographic characteristics across the broad range of sociopolitical attitudes covered by the General Social Survey (GSS). I find that sexual orientation is a substantial and exceptionally consistent predictor of social attitudes, and that identity-related processes explain the consistent attitudinal gaps between sexual minorities and heterosexuals.

\section{GENDER, RACE, AND SEXUALITY}

Given the focus of much current sociological research, one might assume gender and race have long been at the core of sociology. But the centering of gender and race is a relatively new development. Sociology has been historically dominated by white men, and early stratification research primarily focused on class inequality. Women and racial minorities such as Jane Addams and W. E. B. Du Bois made important and foundational contributions to the field, but these contributions were often marginalized (Morris 2015) and gender and race long remained marginal topics (Stacey and Thorne 1985). Even when the discipline began to pay more attention to gender and race, sociology was still said to be behind other disciplines such as anthropology, history, and literature (Stacey and Thorne 1985). In fact, it was not until the 1990s that we reached the type of central focus on gender and race present in the discipline today.

Figure 1 illustrates how gender and race were not but came to be central factors published in what are often thought to be the "core" general sociological journals, where importance to the 
entire discipline is considered a prerequisite for publication: American Sociological Review (founded in 1936, the most recent of the three journals), American Journal of Sociology, and Social Forces. ${ }^{1}$ Race and gender did not receive regular core focus until the 1970s, and became central themes only in the 1990s. Since the 1990s, gender and race have been at the center of mainstream sociology, with both becoming the topic of growing numbers of articles in these core generalist journals.

[Figure 1]

Gender and race are now central factors by which we understand the social world, and a survey or study without these factors included at least among a standard battery of sociodemographic items would be considered incomplete. Sexuality, however, has only recently become a regular part of some national surveys - the General Social Survey, for example, first asked about self-identified sexual orientation in 2008, and the U.S. Census still does not ask about sexual orientation - and as shown in Figure 1 sexuality was the topic of little to no core articles until the 1990s. It was not until the 2010s that the core journals began regularly publishing a couple sexuality articles annually. Compared to gender and race, sexuality clearly remains marginal with very few articles on the topic published in $A S R, A J S$, or $S F$ in any given year. In this study, I examine the impact of sexual orientation across attitudinal items to determine if it is generally unimportant to people's outlook — which might justify the marginalized status of the study of sexuality—or, instead, if it is a central social divide that strongly predicts social attitudes. If it is a key factor in people's lives that strongly predicts their

\footnotetext{
${ }^{1}$ Figure 1 presents the four-year moving average of the number of articles on a given topic published in $A S R$, AJS, and $S F$. The numbers come from a Web of Science search with each of the topics as the search term. See figure caption for more information.
} 
outlook on the world, I propose that it should be included with gender, race, and class as a central measure in at least the study of attitudes.

\section{SEXUAL ORIENTATION AND ATTITUDES}

Attitudes toward sexual minorities became one of the most vibrant areas of public opinion research in the years leading up to the legalization of same-sex marriage in the United States. Certainly, more of this work is still needed as social conditions change and public opinion continues to shift. However, there is a larger gap in public opinion research on the attitudes of sexual minorities themselves. Early research on sexuality and attitudes relied on small convenience samples and yielded mixed results because large nationally-representative data sets have not always collected data on sexuality (Beran et al. 1992; Corbett, Troiden, and Dodder 1977; Lalonde, Doan, and Patterson 2000; McDonald and Moore 1978), but more recently nationally-representative data have come available that enable broad examinations of sexuality and social attitudes. Yet, compared to what we know about what society thinks about sexual minorities, we know little about what sexual minorities think about society. Is sexuality a generally unimportant factor in how people view the world? Is it important on a limited number of topics, but not something that needs to be considered in research on seemingly unrelated topics? Or could sexuality be a generally important factor that shapes people's views across a broad range of social issues? Past research has provided at least some support for each of these possibilities.

\section{Attitudinal Similarity}

Some studies have suggested that sexual orientation may not be an important factor in social attitudes due to the importance of childhood political socialization or because of other factors and identities superseding sexuality. Childhood socialization is important for party affiliation and 
attitude development with strong links between parents' and children's partisanship and attitudes across the life course (Converse 1964; Glass, Bengtson, and Dunham 1986; Hyman 1959; Jennings and Niemi 1968; Miller and Glass 1989). Whereas race, ethnicity, or religion-based minority values can be transmitted from parents to children over generations, sexual minority values typically cannot be transmitted in this manner (Glass et al. 1986; Jennings, Stoker, and Bowers 2009; Sapiro 2004; Sherrill 1996). Therefore, if family socialization is the key to attitude formation, or if other sociodemographic characteristics — such as educational attainment, which is also influenced by family socialization (Darnell and Sherkat 1997)_overshadow any potential effects of sexuality on attitudes, sexual minorities and heterosexuals may hold very similar attitudes.

Using a large sample of voters from an exit poll, Sherrill (1996) found patterns consistent with a childhood socialization framework. After noting similar political concerns among sexual minorities and heterosexuals, Sherrill (1996) said that attitude similarity is what we would expect from people born into diaspora (i.e., born into a wide range of home environments distributed throughout the country) who face multiple and conflicting pressures and purposes.

\section{Limited Attitudinal Differences}

A second possibility from the public opinion literature suggests that people with shared experiences and interests tied to group statuses will develop distinct attitudes out of rational selfconcern (Bolzendahl and Myers 2004; Egan and Sherrill 2005; Hunt 2007; Schaffner and Senic 2006). For example, women have more liberal gender attitudes (Bolzendahl and Myers 2004) and Blacks more liberal racial attitudes (Hunt 2007). Similarly, despite being liberal on many issues (Bobo and Licari 1989; Hyman and Wright 1979; Lottes and Kuriloff 1994), college graduates can be more conservative on economic issues, holding attitudes that privilege their 
own status and financial well-being (Jackman and Jackman 1983; Phelan et al. 1995; Stubager 2008).

In addition to holding distinct attitudes on specific issues directly tied to their group interests, people will sometimes identify with political parties and general partisan stances (i.e., self-identification as a conservative, moderate, or liberal) thought to benefit their group. For example, despite holding conservative attitudes on some key partisan issues women and Blacks are more likely to identify as liberal and as Democrats (Box-Steffensmeier et al. 2004; Kinder and Winter 2001; Manza and Brooks 1998). Various theories have been proposed for why group members hold this type of self-concern and why it can extend to general partisanship, including individualistic self-interest or socialization into a limited set of shared group interests (Converse 1964; Gilens 2012; Phelan et al. 1995; Stubager 2008).

Based on the patterns for gender, race, and education, as well as previous research on sexual orientation (Egan and Sherrill 2005; Schaffner and Senic 2006), sexual minorities may have more liberal attitudes on issues directly related to sexuality. As with gender- and race-based partisanship, these interests could spill over into liberal identities and Democratic affiliation. Illustratively, Schaffner and Senic (2006) sought to understand why sexual minorities seem more likely to identify as Democrats. They found that LGB concern for their own economic wellbeing — such as acquiring spousal benefits — shaped LGB support for the Democratic Party. Consistent with this pattern, Egan and Sherrill (2005) noted that sexual minorities have greater support for issues directly related to civil liberties and rights for sexual minorities, and Lewis, Rogers, and Sherrill (2011) argued that the LGB population tends to vote for Democratic candidates out of concern for LGB rights and related policy liberalism. 


\section{Attitudinal Differences toward Other Marginalized Groups}

Although people tend to hold attitudes and identify with political parties based on their group interests, it is possible for group members' attitudes to differ on seemingly unrelated issues as well. Positionality approaches to politics suggest structurally-disadvantaged groups may develop attitudes that are positive toward other disadvantaged groups due to shared experiences with and understanding of marginalization and structural inequalities. For example, women and Blacks often hold attitudes that are more sympathetic toward other marginalized groups, and a few related theories have been proposed to explain why (Box-Steffensmeier et al. 2004; Collins 2000; Herek 2002; Hunt 1996, 2007; Kinder and Winter 2001; Manza and Brooks 1998). The "underdog" principle suggests that disadvantaged and/or minority groups are more likely to have liberal attitudes due to sympathy for and understanding of the plight of other disadvantaged groups (Davis and Robinson 1991; Hunt 1996; Schuman and Harding 1963). Similarly, social dominance theory suggests that disadvantaged groups have lower preference for social dominance and hierarchy, and that lower levels of acceptance for social dominance are associated with more positive attitudes toward marginalized groups (Eagly et al. 2004; Sidanius and Pratto 1999).

More recent research, much of it using newly available data on sexuality in the General Social Survey, has found patterns consistent with the possibility that sexual minorities hold attitudes that are sympathetic toward other disadvantaged groups. For example, Cochran and colleagues (2009) considered whether sexual minorities have more other-centered values due to their disadvantaged status. They found small and inconsistent differences between heterosexuals and sexual minorities, with sexual minorities appearing somewhat more liberal. Worthen et al. (2012) said that despite much research on how gender, race, and class relate to attitudes toward the death penalty, no research had examined the impact of sexuality on attitudes toward the death 
penalty. They used the GSS to demonstrate that although the majority of sexual minorities support the death penalty, sexual minorities seem to be a little less likely than heterosexuals to support it. Using the American National Election Study, Grollman (2017) found that sexual minorities tend to have liberal attitudes on race and gender issues. Although most research on sexual orientation and attitudes has focused on attitudes toward sexuality and/or attitudes toward other marginalized groups such as women and racial minorities, a study by Egan (2012) showed that sexual minorities are more likely to identify as liberal, support same-sex marriage, and prioritize environmental protection.

\section{ARGUMENT AND EXPECTATIONS}

Status and positionality theories of social attitudes like the underdog principle suggest that sexual minorities would be liberal on at least certain issues without the need for intergenerational transmission of values. But affirmation of and acculturation into a marginalized sexual minority identity may produce an even more cohesive set of values among sexual minorities than those held by women and racial minorities (Davenport 2016; Egan 2012; Lewis et al. 2011).

Sexual minorities are not only marginalized, but they have been frequently labeled “immoral" by traditional values and institutions. Sexual minorities therefore often face challenges grappling with and affirming their identity, and some people with same-sex desire and traditional beliefs reject LGB identity (Wedow et al. 2017). Identification requires both awareness and acceptance of one's membership in a particular social group, and subsequently promotes attachment to that group's concerns and interests (Davenport 2016; Tajfel 1981). Because it is a marginalized identity often fraught with social costs, especially for those embedded in conservative social contexts, sexual minority identity could be a particularly strong predictor of social attitudes (Egan 2012). People from more progressive backgrounds can be 
more likely to affirm a sexual minority identity, and the experience of recognizing and affirming that identity could shape sexual minorities' social outlook (see Baunach and Burgess 2013; Brown-Saracino 2015; Wedow et al. 2017 on affirmation of sexual minority identity).

Beyond the importance of identity affirmation for shaping social attitudes, identity acculturation could further reinforce the importance of sexual identity (Lewis et al. 2011). Attitudinal acculturation is assimilation into a sociopolitical subculture's shared set of beliefs and values through adult socialization processes and experiences, such as the experience of coming out, shared marginalization, intra-group contact, and the development of group commitment (on the importance and dynamics of sexual minority identities, subcultures, and intra-group contact, see Armstrong 2002; Brown-Saracino 2015). Both identity affirmation and identity acculturation processes lead me to expect that sexual minorities will be more liberal than heterosexuals and that sexual identity will predict liberal attitudes more strongly than sexual behavior:

EXPECTATION 1: Sexual minorities will be more liberal than heterosexuals. EXPECTATION 2: Sexual identity will predict liberal attitudes more strongly than sexual behavior.

In addition to different identity-affirmation processes, different experiences with “othering" processes may lead sexual minorities to have a more cohesive set of marginalizedgroup-based values than those held by women and racial minorities. American women and racial minorities seek and find compensation for their lack of social status in religion (Du Bois 1903; Davis 1971; Ellison and Sherkat 1995; Schnabel 2016b), and subsequently tend to hold some conservative moral and religious values and often recognize religious authority over scientific authority (Lewis 2003; Schnabel 2017; Thornton and Young-DeMarco 2001). Whereas other marginalized groups find acceptance and support in religion, the frequent exclusion and condemnation of sexual minorities by some religious groups (Schnabel 2016a; Sherkat et al. 
2011), sexual minorities' lesser religiosity (Sherkat 2002, 2017), and the linking of religious values and beliefs about partisan issues such as science (O’Brien and Noy 2015; Sherkat and Ellison 2007) could contribute to LGB Americans holding consistently liberal values across social issues - including those on which women and racial minorities are sometimes more conservative. $^{2}$

Therefore, due to distinctive identity processes and social experiences not faced by some other disadvantaged groups, sexual minorities could have liberal attitudes on a broader range of issues than women and racial minorities (or, possibly, even across all types of attitudes measured in social surveys):

EXPECTATION 3: Sexual minorities will hold more consistently liberal attitudes than women and racial minorities.

\section{DATA AND METHODS}

This study tests the above expectations using the General Social Survey. The GSS is a nationally-representative cross-sectional survey of non-institutionalized U.S. adults fielded from 1972 to 2016 (Smith et al. 2015). It is one of the most widely used surveys in social scientific research and includes one of the broadest ranges of sociopolitical attitudes (Fischer and Hout 2006; Freese et al. 1999; Hout and Fischer 2002; O’Brien and Noy 2015; Smith et al. 2006). Since 1991, the GSS has included a measure of sexual partnering behavior and, since 2008, a measure of self-identified sexual orientation. The availability of both measures of sexuality in the GSS provides a unique opportunity to compare the attitudes of sexual minorities and heterosexuals across a broad range of attitudes using nationally-representative data, verify the

\footnotetext{
${ }^{2}$ Many sexual minorities are religious and even more are spiritual, but they have frequently reinterpreted religious teachings with emphasis on love, social justice, and inclusivity (Sherkat 2002; Wedow et al. 2017).
} 
patterns with separate measures (one constructed from behavior and the other based on selfidentification), and even compare the predictive power of behavior and identity when they differ.

\section{Dependent Variables}

This study considers as broad a range of issues as possible to examine whether and to what extent sexual orientation shapes how people view society. The GSS provides a particularly wide array of attitudes on a number of topics including political affiliation and identity, sexuality, gender and family, race, economy and role of government, crime and discipline, free speech, immigration and nationalism, confidence in institutions, science, and religion and morality. The analyses focus on both individual items and topical scales. I first presents patterns for a few key measures and scales (including a seven-point measure of general political views with options ranging from extremely conservative $=1$ to extremely liberal $=7$ ), then standardized summative scales of a number of general topics, and finally summary patterns for the range of items covered by the GSS. To organize the GSS attitude measures into topical scales based on key sociopolitical topics, I drew on past research, the design of the GSS (measures on the same topic are often fielded together), and scaling and fit procedures including diagnostic factor analyses (for similar approaches and attitudinal categories when using the GSS to present broad patterns, see Freese et al. 1999; Hout and Hastings 2014).

\section{Independent Variables}

The key independent variable is sexual orientation, or the sex(es) and/or gender(s) people are attracted to. I measure sexual orientation, an underlying variable, with two proxies: self-reported partnering behavior (available 1991-2016) and self-identified sexual orientation (available 20082016). In both cases, sexuality was asked as part of a confidential self-administered portion of the survey and is coded here as a category of sexual minorities inclusive of lesbians, gays, and 
bisexuals compared to heterosexuals. For behavior, those who reported a same-sex partner in the last five years are considered sexual minorities (see Smith 2006 on this measure and method of using it). Self-identified orientation, the focus of most analyses, is fielded as follows: "Which of the following best describes you? (1) Gay, lesbian, or homosexual, (2) bisexual, or (3) heterosexual or straight." I also consider the impact of gender (woman=1), race and ethnicity (non-Latinx white=1, non-Latinx Black=1, Latinx=3, and non-Latinx "other race"=4), and education (college degree $=1)^{3}$ across social attitudes. Table 1 presents descriptive statistics for these measures.

[Table 1]

Religion and general political orientation, as outlook-shaping schemas, are ideological factors that could operate as key pathways by which sexuality could shape attitudes (Boutyline and Vaisey 2017; Schnabel 2017). Religion measures include religiosity (a commonly-used scale of religious salience, attendance frequency, and prayer frequency) and a categorical measure of the level of fundamentalism of respondents' religious affiliation. ${ }^{4}$ I measure general political views with the measure noted above that asks respondents to place themselves on a scale from extremely conservative to extremely liberal. ${ }^{5}$

\footnotetext{
${ }^{3}$ Education is a commonly used measure of social class that remains consistent over the life course, tends to be reported accurately with little missing data, and is a particularly strong predictor of social attitudes, and I measure education with a binary for college because credentials tend to be more important than years of education, having a bachelor's degree is a key measure of social class, and this dichotomization will be comparable with the other dichotomous predictors (Krieger, Williams, and Moss 1997; Lottes and Kuriloff 1994; Stubager 2008). Coding education in years or in multiple categories yields similar patterns.

${ }^{4}$ I use the GSS-formulated religious categorization scheme described by Smith (1990), director of the GSS, because it does not conflate religion and race, which is a key factor in this study. Scholars have argued that categorization schemes with a "Black Protestant" category do not conflate religion and race, but the correlation between Black and "Black Protestant" in the RELTRAD scheme is about the same as the correlation between sexual behavior and sexual orientation (.7). Although not all Blacks are "Black Protestants," almost all "Black Protestants" are Black. ${ }^{5}$ Because religion and general political orientation are ideological factors - rather than basic sociodemographic characteristics like the other items - and because this study's focus is general group differences in attitudes, I do not
} 


\section{Analytic Strategy}

I first compare the impact of sexual behavior (had a same-sex partner in the last five years=1) and sexual identity $(\mathrm{LGB}=1)$ on general political views. I subsequently examine attitudinal differences between sexual minorities and heterosexuals over time and then across social issues. Attitudinal differences by sexuality across issues are contextualized in relation to attitudinal differences by two ascribed characteristics (gender and race) and one achieved characteristic (education). All models include sexual orientation (measured as partnering behavior and/or selfidentification), gender, race/ethnicity, education, age (continuous), and a series of dichotomous controls for period effects (i.e., survey year). ${ }^{6}$ Missing data on covariates are imputed. ${ }^{7}$ Logistic regression is used for binary outcomes, ordered logistic regression for ordered items, and OLS for continuous measures including the attitude scales. Multinomial logistic regression is used for items with three or more non-ordered categories.

\section{RESULTS}

\section{Sexual Behavior, Sexual Identity, and General Political Orientation}

The availability of two distinct measures of sexuality, behavior and identity, from 2008 to 2016 provides a unique opportunity to examine the expected importance of affirmed identity in the relationship between sexuality and social attitudes. As shown in Table 2, sexual behavior and sexual identity are both strong predictors of political views, with sexual minorities substantially

include these items in all analyses. In other words, these are potential intermediary factors that help explain why group differences exist rather than just basic controls like age or survey year.

${ }^{6}$ Sensitivity analyses with additional covariates — including marital status, parental status, region, and ruralityyielded equivalent patterns.

${ }^{7}$ The presented results use regression methods for single imputation. Additional analyses employing multiple imputation yielded equivalent results. The sample for each analysis varies by the number of people asked each of the dependent variables. The vast majority of missing data on outcome measures are due to the split ballot and module format of the GSS - items are administered to random subsets of the total sample on different questionnaire versions in any given year, and many questions are not fielded in all survey years. 
more liberal than heterosexuals. This pattern lends initial support to Expectation 1 that sexual minorities are more liberal than heterosexuals. Of note, those with no partnering information hold equivalent political identities to those with opposite-sex partners only (due to similarity here and in other analyses, later results combine opposite-sex-partners-only and no-partneringinformation in a no-same-sex-partners group). Despite similar overall patterns for behavior and identity, when both are included in the same model it is clear that LGB identity is the stronger predictor of political views.

\section{[Table 2]}

Figure 2 shows how behavior and identity relate to political views when they differ. As illustrated in the figure, those who are sexual minorities on just identity ${ }^{8}$ hold similar political ideologies to respondents who are sexual minorities on both behavior and identity, whereas people who are sexual minorities on just behavior are similar to heterosexuals. Therefore, the impact of sexuality on attitudes appears to operate through LGB identity, which provides support for Expectation 2 that self-identification is key in the relationship between sexual orientation and social attitudes. As will be noted later, this same distinction occurs across attitudinal outcomes, with behavior and identity each predicting outcomes individually, but identity being the primary predictor when behavior and identity differ.

[Figure 2]

\section{Sexual Minority Politics over Time}

Focusing on the time period from 2008 to 2016 when measures of both behavior and identity were available, we have seen that sexual orientation matters and that identity is the key factor in

\footnotetext{
${ }^{8}$ The vast majority of sexual minorities by identity but not behavior identified as bisexual (76\%) and/or did not have a partner in the last five years (34\%).
} 
predicting liberal politics. I next consider whether sexual orientation has mattered over time using the behavior measure available from 1991 to 2016. Certainly, sexual minority politics evolve over time in both emphasis and approach, but the general attitudinal pattern I find is that sexual minorities have been consistently more liberal than heterosexuals over time. I considered patterns over time for a broad range of issues and present results for two key political outcomes in Figure 3. Panel A shows that sexual minorities have held consistently more liberal general political views than heterosexuals from the early 1990s through 2016. Small samples in any given year produce some fluctuation, but there is no overall change trend. Instead, sexual minorities have been and continue to be consistently more liberal than heterosexuals.

[Figure 3]

Whereas there was no convergence or divergence in sexual minority vs. heterosexual attitudes on most social issues, there is an interaction effect between year and sexuality on views toward same-sex marriage. As illustrated in Figure 3 Panel B, the reason for this interaction effect is that heterosexuals — who had more room to liberalize - have liberalized more quickly than sexual minorities. There may have been a shift on this issue among sexual minorities earlier on, but support for same-sex marriage rights has been similarly high among sexual minoritieswith a mean viewpoint between supporting and strongly supporting same-sex marriage_-across the available years.

Sexual minority politics shift over time, both in focus and in approach. But despite variation in focus and approach, the general story over time is that sexual minorities are and have been more liberal than heterosexuals as long as the GSS has been collecting data on sexual partnering behavior. 


\section{Attitudes across Issues}

Having established that sexual minorities have held substantially more liberal political identities than heterosexuals over time, I now consider the extent to which sexual minorities are liberal across issues. Other disadvantaged groups are liberal across a number of issues, but can be just as if not more conservative on certain issues, including some linked to traditional religious values (Schnabel 2017). Are sexual minorities, like women and racial minorities, liberal on some issues but not others? Or, alternatively, are sexual minorities consistently liberal across issues as expected in an identity affirmation and acculturation framework?

Table 3 presents patterns for the impact of sexual orientation (measured with selfidentification), gender, race, and education on three issues closely tied to religious values and on which some structurally-disadvantaged groups may not be more liberal: abortion, suicide, and science. The models first present the patterns for the key statuses with controls and then add potential pathways by which the social statuses could predict attitudes. On the first outcome measure, an abortion attitudes scale, sexual minorities are .36 of a standard deviation more liberal than heterosexuals. When accounting for religion — as measured by religiosity and religious fundamentalism - this sexual orientation gap is significantly attenuated to a .22 standard deviation difference. This attenuation suggests that the lower levels of religiosity and fundamentalist affiliation among sexual minorities is a key pathway by which sexuality predicts attitudes. Accounting for general political views further attenuates the relationship between sexuality and abortion attitudes. Although the difference by sexuality is less than half as large as it was before accounting for religion and political orientation, a significant .14 standard deviation difference between sexual minorities and heterosexuals persists in the full model.

[Table 3] 
Whereas women and racial minorities have more liberal general political views, they are not more liberal on abortion. In fact, women and Latinxs are significantly more opposed to abortion than their counterparts. After accounting for religion, however, women and Blacks appear significantly more supportive of abortion rights and Latinx opposition is significantly attenuated. Therefore, it appears that if it were not for religion suppressing their liberal attitudes (see Schnabel 2017), women and Blacks would hold abortion attitudes more similar to those of sexual minorities. In fact, religion appears to do more to suppress the liberal views of women and Blacks than it does to mediate the views of sexual minorities. College, like sexual orientation, predicts liberal abortion attitudes, and this education difference persists when accounting for religion and political views.

Turning from abortion to suicide, we see very similar patterns, though women and racial minorities are even more opposed to suicide than abortion. Sexual minorities are substantially more liberal than heterosexuals, and some of the difference can be explained by religion and political orientation. Women and racial minorities are generally opposed to suicide, which is in part explained by religion. College graduates are consistently liberal across models.

We again see similar patterns for science attitudes. Sexual minorities hold more liberal science attitudes, and much of this difference can be explained by religion and political orientation. In fact, there is no longer a significant difference by sexual orientation after accounting for these factors. Women and Blacks are again more conservative, and this difference can be explained by religion. College is, once again, a significant predictor of liberal attitudes across models. Providing initial support for Expectation 3, sexual minorities are more consistently liberal than women and racial minorities on issues linked to traditional religious values. 
Whereas Table 3 focused on issues closely tied to specific religious teachings, Table 4 presents patterns for three key contemporary issues less closely tied to specific religious teachings: race, free speech, and marijuana legalization. Sexual minorities are .29 of a standard deviation more liberal than heterosexuals on the race attitudes scale. Accounting for religion slightly attenuates the relationship and accounting for political orientation significantly attenuates the relationship, suggesting that the liberal general political orientation of sexual minorities helps explain their liberal racial attitudes. Nevertheless, a significant and substantial .15 standard deviation difference between sexual minorities and heterosexuals persists in the full model. Gender, race, and education are also significant predictors of racial attitudes, with women, racial minorities, and those with a college degree holding more liberal views than their counterparts.

\section{[Table 4]}

Shifting from attitudes toward a structurally-disadvantaged group (racial minorities) to free speech, we see that sexual minorities are once again more liberal. Religion and political views again appear to operate as pathways by which sexual orientation predicts attitudes, and again a significant difference persists in the full model. Similar to the patterns for issues closely linked to specific religious teachings, women and racial minorities are more conservative than their counterparts on free speech and religion helps explains women and Blacks' conservative free speech views. College graduates are again consistently liberal.

Finally, turning to support for the legalization of marijuana we see odds ratios that indicate sexual minorities are much more likely to support marijuana legalization than heterosexuals, and that a substantial sexuality gap persists when accounting for religion and political orientation. Women and Latinxs are significantly more conservative on marijuana, 
whereas Blacks do not differ significantly from whites. And, again, religion seems to be suppressing the liberal views among other disadvantaged groups, and especially Blacks, more than it mediates the liberal views of sexual minorities. Breaking from the patterns for the other issues, college does not have a significant impact on marijuana attitudes. Providing further support for Expectation 3, sexual orientation appears to be a more consistent predictor of liberal attitudes than gender, race, and even college on these key contemporary social issues.

The issues presented above are important, but substantiating the argument that people's sexuality is as important as their gender, race, or education for understanding their social attitudes requires looking across as many issues as possible. Table 5, therefore, summarizes analyses on eight additional general topics covered by the General Social Survey. Sexual minorities are more liberal across all topics, and the impact of sexuality is both significant and substantial: on every topic sexual minorities are at least .2 of a standard deviation more liberal than heterosexuals. These patterns confirm that sexual minorities are more liberal across a broad range of social issues. The issues most strongly predicted by sexual orientation are general partisanship, sexuality, and religion and morality.

\section{[Table 5]}

Women and racial minorities are more liberal than their counterparts on some topics, no different on others, and even more conservative on several topics. Consistent with the earlier patterns that showed how religion can suppress the liberal politics of women and racial minorities on issues tied to traditional morality, women, Blacks, and Latinxs are all significantly more conservative than their counterparts on sexuality and on religion and morality. Moreover, Latinxs and those in the GSS "other race" category are more conservative on issues of gender and family. Additional analyses suggest that religion is an important part of why women and 
racial and ethnic minorities are more conservative on certain issues. College is a more consistent predictor of liberal attitudes than gender and race. However, on some topics-including general partisanship and the economy and role of government - college is a weaker predictor of attitudes than sexual orientation. Therefore, in support of Expectation 3 sexual orientation is a distinctly consistent and substantial predictor of attitudes across a broad range of issues. In further support of Expectation 2, additional analyses including both sexual behavior and sexual identity in models predicting these attitudes scales, and those presented earlier, demonstrate that identity is the key independent predictor of liberal attitudes.

As a further consideration of the impact of sexual orientation across the range of social attitude measures in the General Social Survey, Figure 4 summarizes the patterns for the impact of sexuality—as measured by self-identification — on 101 individual attitudinal items, some of which were only available in certain years or did not fit well with other measures and thus were not included in the issue scales. ${ }^{9}$ Sexual minorities are significantly more liberal on $78 \%$ of these measures. ${ }^{10}$ They are not significantly more conservative on any items. Irrespective of significance, LGB respondents are more liberal than heterosexuals on 99\% of items (100 of 101 total items). ${ }^{11}$ Additional analyses considered the impact of sexuality as measured by behavioravailable from 1991-2016 — on a larger number of items (233 attitude measures) and found the same patterns: sexual minorities were more liberal on $100 \%$ of items significantly predicted by sexuality, and more liberal on $99 \%$ of items irrespective of significance. Consistent with the patterns presented earlier, additional analyses show that religion and general political orientation

\footnotetext{
${ }^{9}$ To be included here items had to be available in multiple surveys from 2008 to 2016 and be correlated with the political views measure.

${ }^{10}$ The "liberal" position on many attitude items is self-evident, but I cross-checked all items with the general political views measure (responses positively associated with liberal political views are considered "liberal"). Nonpartisan-typed issues (i.e., those not associated with political orientation) were excluded.
} 
are key pathways that help explain why sexual minorities are so consistently liberal across individual attitude items.

\section{[Figure 4]}

As a point of comparison, Figure 4 shows that gender has a significant impact on 76 of the 101 items, but women are more liberal than men on only half of these items. Race is also an important predictor of social attitudes, but like gender it is not as consistent a predictor as sexuality. Education is a very consistent predictor of liberal attitudes with college graduates significantly more liberal on 77 items. Nevertheless, college graduates are also significantly more conservative than those with less education on eight items, including measures related to government spending, economic redistribution, organized labor, and police violence. Whereas sexual minorities trended toward the liberal position on issues irrespective of significance on $99 \%$ of the 101 total items, women trended toward the more liberal position on $50 \%$ of the items, Blacks 52\%, Latinxs 38\%, and college graduates $86 \%$. Therefore, while gender and race are key predictors of social attitudes and predict liberal identity and voting, they are less consistent predictors of liberal attitudes toward specific social issues. ${ }^{12}$ Education is a more consistent predictor than gender or race, but sexual orientation stands out as a substantial and exceptionally consistent predictor of social attitudes.

\section{Ancillary Analyses}

I conducted a number of ancillary analyses and report some of the more important additional findings here. Intersectionality theory suggests the impact of sexuality could vary by gender,

\footnotetext{
11 The only item on which the coefficient is toward conservatism is confidence in education as an institution, which liberals typically have more confidence in.

12 Additional analyses show that religion helps explain why women and racial minorities are not more consistently liberal across individual issues (see Schnabel 2017).
} 
race/ethnicity, or education. Therefore, I examined interactions between sexuality-measured both as behavior and as identity — and these factors on the attitude scales. I found larger attitudinal differences by sexual minority status among people advantaged on other statuses, which could be due to people already having one marginalized identity, and thus a greater awareness of structural inequality, so that additional disadvantaged statuses may not have as large of a liberalizing impact.

Because research should consider effect size in addition to significance to determine the importance of a predictor, I conducted postestimation tests to compare the size of attitude differences by sexuality to those for gender, race, and education. Similar to sexual orientation being a more consistent predictor of liberal attitudes than gender and race, it is also generally a more substantial predictor. And similar to both sexual orientation and college consistently and significantly predicting attitudes, they also both have large impacts that are, on the whole, on par with one another.

As noted above, I considered the comparative importance of sexual behavior and identity across issue topics and found identity is the key factor by which sexuality predicts attitudes. In addition to the patterns across the individual issues and author-constructed topical scales presented above, I also considered patterns across a number of GSS-formulated scales and found similar patterns with sexual minorities consistently, significantly, and substantially more liberal across scales (and identity again the key measure of sexuality).

Finally, additional analyses with sexuality in three categories ([1] lesbian/gay, [2] bisexual, and [3] heterosexual) demonstrated that the attitudes of lesbian/gay and bisexual respondents are typically similar, and that both the gay/lesbian and bisexual respondents differ from heterosexuals. On the rare individual items where LG and B respondents differ from one 
another, lesbian/gay respondents tend to be more liberal than bisexual respondents. The overall patterns are clear. Regardless of whether lesbian/gay and bisexual respondents are combined or separated when compared to heterosexuals, and regardless of whether sexuality is measured as behavior or self-identification, sexual minorities are consistently more liberal than heterosexuals across a broad range of social attitudes.

\section{DISCUSSION}

Gender, race, and class are core factors by which we understand the foundations of social attitudes and are obligatory measures in social research. Although scholarly emphasis on sexual orientation is growing, most research has focused on sexual minorities as social objects rather than social subjects. The evidence presented in this study supported each of the three expectations: (1) sexual orientation matters for attitudes, (2) identity is key to why sexual orientation matters, and (3) sexual orientation consistently predicts attitudes across issues. Sexual orientation is, therefore, a fundamental social divide that shapes a broad range of sociopolitical attitudes. With the theory set forth and the patterns already demonstrated, it may not be surprising that sexual minorities would be more liberal than heterosexuals on at least some items. What is surprising, however, is the exceptional consistency of sexuality's relationship with social attitudes, which is not matched by gender, race/ethnicity, or even education. I argue that sexuality should join gender, race, and class as a central and standard factor by which we conceptualize and systematize the social world, and at least attitudinal research should be considered incomplete without it.

The patterns I demonstrated for gender and race are generally consistent with positionality and identity theories of politics (Davenport 2016; Davis and Robinson 1991; Hunt 1996; Worthen et al. 2012). Disadvantaged group status helps explain why women, racial 
minorities, and sexual minorities are more liberal, and identity affirmation and acculturation processes can help explain why sexual minorities are more consistently liberal than other disadvantaged groups. Similar to the distinction between having interracial parents and identifying as biracial (Davenport 2016), there is a distinction between being attracted to people of the same gender and affirmation of a sexual minority identity (Armstrong 2002; Baunach and Burgess 2013; Brown-Saracino 2015). Identity explanations, such as identity affirmation (Egan 2012) and acculturation (Lewis et al. 2011), emphasize the importance of identity in a process moving from affirmation of a marginalized identity, subsequent intra-group contact, increasing group commitment, and, finally, attitudinal assimilation and cohesion. Therefore, sexual orientation differences in attitudes could be attributable, at least in part, to a sexual minority subcultural identity shaped by shared experiences with disadvantage, religious marginalization, and ongoing attempts to gain rights in a polarized political context linking cohesive sets of “conservative" and "liberal" attitudes (Baldassarri and Gelman 2008; DellaPosta, Shi, and Macy 2015; Egan 2012; Schnabel 2017; Valelly 2012).

Just as gender, race, and class are key divides by which people experience and approach their social world differently, sexual orientation is a salient identity by which people's life experiences and worldviews differ. Social scientific research often disregards sexual minorities similar to how racial minorities were disregarded in the past. Early social science often focused on whites or failed to seriously consider race as a key social factor because racial minorities were a small proportion of the population. Scholars now recognize that groups should not be ignored in quantitative research simply because they are a minority. Consequently, the argument that heterosexuals make up the majority of the population is not a sufficient justification to render invisible the unique status, experiences, and perspectives of sexual minorities. As several critical 
theorists of knowledge have argued, the "other" has an important outlook because they of necessity have an awareness of both the margin and the center (Collins 2000; Hooks 2000). The unique perspective of sexual minorities, like that of women and racial minorities, could be used to conceptualize sociopolitical processes. Illustrating the potential real-world impact of considering the perspective of sexual minorities, even a small number of openly gay legislators can have "a transformative effect" on the attitudes and voting behavior of heterosexual colleagues (Reynolds 2013:259).

Sexual minorities are and have been consistently more liberal than heterosexuals across a broad range of issues, but social change could make their attitudes less distinctive. Research on attitudes toward sexual minorities shows that Americans are becoming consistently more accepting (Adamczyk and Pitt 2009; Baunach 2012; Powell et al. 2010; Schnabel 2016a; Sherkat et al. 2011), and the legalization of same-sex marriage symbolizes a shift in the position of sexual minorities in American society. As they potentially face less disadvantage and are more assimilated into the mainstream, sexual minorities' attitudes could become less distinctive. In fact, some prominent pundits, LGBTQ activists, and scholars argue that adopting the marriage rights and practices of heterosexuals marks a shift from sexual minority outsider identity, community, and culture to a loss of distinctiveness (Bernstein 2015; Bernstein and Taylor 2013; Ghaziani 2011; Kantor 2015). ${ }^{13}$

Future research will need to grapple with the question of what will happen to U.S. sexual minority politics post same-sex marriage. Being accepted by mainstream culture does not cause all minority cultures to assimilate, but being a sexual minority is different from being a racial,

\footnotetext{
${ }^{13}$ As rights are gained and acceptance is possible without dedicated safe spaces, some sexual minorities wonder whether they will lose "the specialness of being gay" and what they will "have in common when they don't have oppression" (Kantor 2015; also see Sullivan 2005).
} 
ethnic, or religious minority. Whereas distinctive racial, ethnic, or religious values can easily be transmitted across generations via family socialization, sexual minority values typically are not transmitted in this way (Sherrill 1996). Moreover, there are fewer rituals in sexual minority culture than among some racial, ethnic, and religious minority cultures. If shared marginalization were to fully cease, sexual minorities will no longer be underdogs, recognizing a sexual minority identity and coming out will be less significant experiences, and sexual minority identity will be less distinctive. Therefore, sexual minority's attitudes may become more like those of heterosexuals. Alternatively, continued opposition illustrated by denial of business services, a lack of informal privileges, and continued threats of violence may cause attitudes to remain distinctive (Doan et al. 2014; Powell, Quadlin, and Pizmony-Levy 2015; Powell et al. 2017). Or, like American Jews who have remained more liberal even as they gained more rights and social acceptance (Schnabel and Sevell 2017; Simon 1978), LGB Americans could retain their consistent and substantial attitudinal distinction now that they have a group identity tied to liberal politics and concern for disadvantaged others.

The possibility of measurement error in minority classification can distort patterns in research on minority groups (Cheng and Powell 2005) and is thus a potential limitation to this study. If some heterosexuals are categorized as sexual minorities and some sexual minorities as heterosexuals, this misclassification will have a larger impact on the minority group and make them seem more like the majority group. If some heterosexuals inaccurately indicated they are sexual minorities the results reported in this study could have underestimated attitudinal differences between sexual minorities and heterosexuals. ${ }^{14}$

\footnotetext{
14 The possibility of underestimation of attitudinal differences is exacerbated by a possible correlation between not understanding survey questions about sexuality (e.g., not recognizing that one is heterosexual or that bisexual means attraction to both men and women rather than a relationship between an opposite-sex pair) and conservatism.
} 
Sexual orientation, although rarely considered in attitudinal research, is an exceptionally consistent predictor of public opinion. The patterns demonstrated in this study are consistent with a marginalized identity explanation of social attitudes. Sexuality predicts attitudes at least as consistently, significantly, and substantially as gender, race, and education and should join these as a core factor by which we understand society and the people who compose it. Accordingly, surveys should include sexual orientation among any standard battery of demographic questions, studies that consider gender, race, and class - even just as standard covariates - should also consider sexuality, and sexuality should become a more central topic of investigation in the social sciences. ${ }^{15}$

\footnotetext{
15 The recommendation to regularly consider sexual orientation raises a couple of practical questions. First, how should sexual orientation be measured? Although self-identification is more influential than partnering behavior when both are in the same model, when considered separately both measures are substantial and consistent predictors of social attitudes and provide similar general patterns. Therefore, while I would recommend using selfidentification when possible, either measure could be used to yield similar conclusions. Second, how should missing data be addressed? Surveys such as the GSS have sometimes fielded sexual orientation questions to subsets of the full sample, and some respondents refuse to answer or say they do not know. Imputation is commonly used to address missing data, but imputation assumptions are violated if the data are not missing at random. Given that sexual orientation is a categorical variable, researchers could simply include a missing category and not lose cases or violate assumptions.
} 


\section{REFERENCES}

Adamczyk, Amy. 2017. Cross-National Public Opinion about Homosexuality: Examining Attitudes across the Globe. Berkeley: University of California Press.

Adamczyk, Amy and Cassady Pitt. 2009. "Shaping Attitudes about Homosexuality: The Role of Religion and Cultural Context." Social Science Research 38(2):338-51.

Armstrong, Elizabeth. 2002. Forging Gay Identities: Organizing Sexuality in San Francisco, 1950-1994. Chicago, IL: University of Chicago Press.

Baldassarri, Delia and Andrew Gelman. 2008. "Partisans without Constraint: Political Polarization and Trends in American Public Opinion." American Journal of Sociology 114(2):408-46.

Baunach, Dawn Michelle. 2012. "Changing Same-Sex Marriage Attitudes in America from 1988 Through 2010." Public Opinion Quarterly 76(2):364-78.

Baunach, Dawn Michelle and Elisabeth Burgess. 2013. "Sexual Identity in the American Deep South: The Concordance and Discordance of Sexual Activity, Relationships, and Identities." Journal of Homosexuality 60(9):1315-35.

Beran, Nancy, Connie Claybaker, Cory Dillon, and Robert Haverkamp. 1992. "Attitudes toward Minorities: A Comparison of Homosexuals and the General Population." Journal of Homosexuality 23(3):65-83.

Bernstein, Mary. 2015. "Same-Sex Marriage and the Future of the LGBT Movement." Gender \& Society 29(3):321-37.

Bernstein, Mary and Verta Taylor. 2013. The Marrying Kind? Debating Same-Sex Marriage within the Lesbian and Gay Movement. Minneapolis, MN: University of Minnesota Press.

Bobo, Lawrence and Vincent Hutchings. 1996. "Perceptions of Racial Group Competition: Extending Blumer's Theory of Group Position to Multiracial Social Context." American Sociological Review 61(6):951-72.

Bobo, Lawrence and Frederick Licari. 1989. "Education and Political Tolerance.” Public Opinion Quarterly 53(3):285-308.

Du Bois, W. E. B. 1903. The Souls of Black Folk. Chicago: A. C. McClurg \& Co.

Bolzendahl, Catherine and Daniel Myers. 2004. "Feminist Attitudes and Support for Gender Equality: Opinion Change in Women and Men, 1974-1998." Social Forces 83(2):759-90.

Boutyline, Andrei and Stephen Vaisey. 2017. "Belief Network Analysis: A Relational Approach to Understanding the Structure of Attitudes.” American Journal of Sociology 122(5):13711447.

Box-Steffensmeier, Janet, Suzanna DeBoef, and Tse-min Lin. 2004. "Dynamics of the Partisan Gender Gap.” American Political Science Review 98(3):515-28.

Brooks, Clem and Jeff Manza. 1997. "Social Cleavages and Political Alignments: U.S. Presidential Elections, 1960 to 1992." American Sociological Review 62(6):937.

Brown-Saracino, Japonica. 2015. "How Places Shape Identity: The Origins of Distinctive LBQ Identities in Four Small U.S. Cities.” American Journal of Sociology 121(1):1-63. 
Cheng, Simon and Brian Powell. 2005. "Small Samples, Big Challenges: Studying Atypical Family Forms.” Journal of Marriage and Family 67(4):926-35.

Cochran, Susan, Vickie Mays, Heather Corliss, Tom Smith, and Joseph Turner. 2009. "SelfReported Altruistic and Reciprocal Behaviors among Homosexually and Heterosexually Experienced Adults." AIDS Care 21(6):675-82.

Collins, Patricia Hill. 2000. Black Feminist Thought: Knowledge, Consciousness and the Politics of Empowerment. New York: Routledge.

Converse, Phillip. 1964. "The Nature of Belief Systems in Mass Publics." in Ideology and Discontent, edited by David Apter. New York: The Free Press.

Corbett, Sherry, Richard Troiden, and Richard Dodder. 1977. "Tolerance as a Correlate of Experience with Stigma: The Case of the Homosexual." Journal of Homosexuality 3(1):314.

Darnell, Alfred and Darren Sherkat. 1997. "The Impact of Protestant Fundamentalism on Educational Attainment." American Sociological Review 62(2):306-15.

Davenport, Lauren. 2016. "Beyond Black and White: Biracial Attitudes in Contemporary U.S. Politics." American Political Science Review 110(1):52-67.

Davis, Angela. 1971. Lectures on Liberation. Los Angeles: National United Committee to Free Angela Davis.

Davis, Nancy and Robert Robinson. 1991. "Men's and Women's Consciousness of Gender Inequality: Austria, West Germany, Great Britain, and the U.S.” American Sociological Review 56(1):72.

DellaPosta, Daniel, Yongren Shi, and Michael Macy. 2015. "Why Do Liberals Drink Lattes?" American Journal of Sociology 120(5):1473-1511.

Doan, Long, Annalise Loehr, and Lisa Miller. 2014. "Formal Rights and Informal Privileges for Same-Sex Couples: Evidence from a National Survey Experiment." American Sociological Review 79(6):1172-95.

Eagly, Alice H., Amanda B. Diekman, Mary C. Johannesen-Schmidt, and Anne M. Koenig. 2004. "Gender Gaps in Sociopolitical Attitudes: A Social Psychological Analysis." Journal of Personality and Social Psychology 87(6):796-816.

Egan, Patrick. 2012. "Group Cohesion without Group Mobilization: The Case of Lesbians, Gays and Bisexuals." British Journal of Political Science 42(3):597-616.

Egan, Patrick and Kenneth Sherrill. 2005. "Marriage and the Shifting Priorities of a New Generation of Lesbians and Gays.” PS: Political Science \& Politics 38(2):229-32.

Ellison, Christopher and Darren Sherkat. 1995. "The 'Semi-Involuntary Institution' Revisited: Regional Variations in Church Participation among Black Americans.” Social Forces 73(4):1415-37.

Fischer, Claude and Michael Hout. 2006. Century of Difference: How America Changed in the Last One Hundred Years. New York: Russell Sage.

Freese, Jeremy, Brian Powell, and Lala Carr Steelman. 1999. "Rebel without a Cause or Effect: Birth Order and Social Attitudes." American Sociological Review 64(2):207. 
Ghaziani, Amin. 2011. "Post-Gay Collective Identity Construction.” Social Problems 58(1):99125.

Gilens, Martin. 2012. Affluence and Influence: Economic Inequality and Political Power in America. Princeton, NJ: Princeton University Press.

Glass, Jennifer, Vern Bengtson, and Charlotte Chorn Dunham. 1986. "Attitude Similarity in Three-Generation Families: Socialization, Status Inheritance, or Reciprocal Influence?" American Sociological Review 51(5):685.

Grollman, Eric Anthony. 2017. "Sexual Orientation Differences in Attitudes about Sexuality, Race, and Gender." Social Science Research 61:126-41.

Herek, Gregory. 2002. “Gender Gaps in Public Opinion about Lesbians and Gay Men.” Public Opinion Quarterly 66(1):40-66.

Hertzog, Mark. 1996. The Lavendar Vote: Lesbians, Gay Men, and Bisexuals in American Electoral Politics. New York: New York University Press.

Hooks, Bell. 2000. Feminist Theory: From Margin to Center. Cambridge, MA: South End Press.

Hout, Michael and Claude Fischer. 2002. "Why More Americans Have No Religious Preference: Politics and Generations." American Sociological Review 67(2):165-90.

Hout, Michael and Orestes Hastings. 2014. GSS Report: Reliability and Stability Estimates for the GSS Core Items from the Three-Wave Panels, 2006 - 2010. Institute for the Study of Societal Issues, University of California at Berkeley.

Hunt, Matthew. 1996. "Individual, Society, or Both? A Comparison of Black, Latino, and White Beliefs about Causes of Poverty." Social Forces 75(1):293-322.

Hunt, Matthew. 2007. “African American, Hispanic, and White Beliefs about Black/White Inequality, 1977-2004.” American Sociological Review 72(3):390-415.

Hutchings, Vincent and Nicholas Valentino. 2004. "The Centrality of Race in American Politics.” Annual Review of Political Science 7(1):383-408.

Hyman, Herbert. 1959. Political Socialization. New York: Free Press.

Hyman, Herbert and Charles Wright. 1979. Education's Lasting Influence on Values. Chicago, IL: University of Chicago Press.

Jackman, Mary. 1994. The Velvet Glove: Paternalism and Conflict in Gender, Class, and Race Relations. Berkeley, CA: University of California Press.

Jackman, Mary and Robert Jackman. 1983. Class Awareness in the United States. Berkeley, CA: University of California Press.

Jennings, M.Kent and Richard Niemi. 1968. "The Transmission of Political Values from Parent to Child." American Political Science Review 62(1):169-84.

Jennings, M.Kent, Laura Stoker, and Jake Bowers. 2009. "Politics across Generations: Family Transmission Reexamined." The Journal of Politics 71:782.

Kantor, Jodi. 2015. "Historic Day for Gays, but Twinge of Loss for an Outsider Culture.” New York Times, June 26. 
Kinder, Donald and Nicholas Winter. 2001. "Exploring the Racial Divide: Blacks, Whites, and Opinion on National Policy." American Journal of Political Science 45(2):439-56.

Krieger, N., D. R. Williams, and N. E. Moss. 1997. "Measuring Social Class in US Public Health Research: Concepts, Methodologies, and Guidelines." Annual Review of Public Health 18(1):341-78.

Lalonde, Richard, Lara Doan, and Lorraine Patterson. 2000. "Political Correctness Beliefs, Threatened Identities, and Social Attitudes." Group Processes \& Intergroup Relations 3(3):317-36.

Lewis, Gregory. 2003. "Black-White Differences in Attitudes toward Homosexuality and Gay Rights.” Public Opinion Quarterly 67(1):59-78.

Lewis, Gregory, Marc Rogers, and Kenneth Sherrill. 2011. "Lesbian, Gay, and Bisexual Voters in the 2000 U. S. Presidential Election.” Politics \& Policy 39(5):655-77.

Longest, Kyle, Steven Hitlin, and Stephen Vaisey. 2013. "Position and Disposition: The Contextual Development of Human Values.” Social Forces 91(4):1499-1528.

Lottes, Ilsa and Peter Kuriloff. 1994. "The Impact of College Experience on Political and Social Attitudes." Sex Roles 31(1-2):31-54.

Manza, Jeff and Clem Brooks. 1998. "The Gender Gap in U.S. Presidential Elections.” American Journal of Sociology 103(5):1235-1266.

McDonald, Gary and Robert Moore. 1978. "Sex-Role Self-Concepts of Homosexual Men and Their Attitudes toward Both Women and Male Homosexuality." Journal of Homosexuality 4(1):3-14.

Miller, Richard B. and Jennifer Glass. 1989. "Parent-Child Attitude Similarity across the Life Course." Journal of Marriage and Family 51(4):991-97.

Morris, Aldon. 2015. The Scholar Denied: W.E.B. Du Bois and the Birth of Modern Sociology. Berkeley: University of California Press.

Mucciaroni, Gary. 2011. "The Study of LGBT Politics and Its Contributions to Political Science.” PS: Political Science and Politics 44(1):17-21.

O'Brien, Timothy and Shiri Noy. 2015. "Traditional, Modern, and Post-Secular Perspectives on Science and Religion in the United States." American Sociological Review 80(1):92-115.

Page, Benjamin and Robert Shapiro. 1992. The Rational Public: Fifty Years of Trends in Americans' Policy Preferences. Chicago, IL: University of Chicago Press.

Phelan, Jo, Bruce Link, Ann Stueve, and Robert Moore. 1995. "Education, Social Liberalism, and Economic Conservatism: Attitudes Toward Homeless People.” American Sociological Review 60(1):126-40.

Powell, Brian, Catherine Bolzendahl, Claudia Geist, and Lala Carr Steelman. 2010. Counted Out: Same-Sex Relations and Americans' Definitions of Family. New York: Russell Sage.

Powell, Brian, Natasha Yurk Quadlin, and Oren Pizmony-Levy. 2015. "Public Opinion, the Courts, and Same-Sex Marriage: Four Lessons Learned.” Social Currents 2(1):3-12. 
Powell, Brian, Landon Schnabel, and Lauren Apgar. 2017. "Denial of Service to Same-Sex and Interracial Couples: Evidence from a National Survey Experiment." Science Advances 3(12):1-7.

Reynolds, Andrew. 2013. "Representation and Rights: The Impact of LGBT Legislators in Comparative Perspective.” American Political Science Review 107(2):259-74.

Sapiro, Virginia. 2004. "Not Your Parents' Political Socialization.” Annual Review of Political Science 7(1):1-23.

Schaffner, Brian and Nenad Senic. 2006. "Rights or Benefits? Explaining the Sexual Identity Gap in American Political Behavior.” Political Research Quarterly 59(1):123-32.

Schnabel, Landon. 2016a. "Gender and Homosexuality Attitudes across Religious Groups from the 1970s to 2014: Similarity, Distinction, and Adaptation." Social Science Research 55(1):31-47.

Schnabel, Landon. 2016b. "The Gender Pray Gap: Wage Labor and the Religiosity of HighEarning Women and Men." Gender \& Society 30(4):643-69.

Schnabel, Landon. 2017. Opiate of the Masses? Social Inequality, Religion, and Politics. Paper presented at Annual Meetings of the American Sociological Association. Available at https://osf.io/preprints/socarxiv/dnz2w/.

Schnabel, Landon and Eric Sevell. 2017. "Should Mary and Jane Be Legal? Americans' Attitudes toward Marijuana and Same-Sex Marriage Legalization, 1988-2014.” Public Opinion Quarterly 81(1):157-72.

Schuman, Howard and John Harding. 1963. "Sympathetic Identification with the Underdog." Public Opinion Quarterly 27(2):230-41.

Schuman, Howard, Charlotte Steeh, Lawrence Bobo, and Maria Krysan. 1997. Racial Attitudes in America: Trends and Interpretations. Revised. Cambridge, MA: Harvard University Press.

Sherkat, Darren. 2002. "Sexuality and Religious Commitment in the United States." Journal for the Scientific Study of Religion 41(2):313-23.

Sherkat, Darren. 2017. "Sexuality and Religious Commitment Revisited: Exploring the Religious Commitments of Sexual Minorities from 1991-2014." Journal for the Scientific Study of Religion. Online 1st.

Sherkat, Darren and Christopher Ellison. 2007. "Structuring the Religion-Environment Connection: Identifying Religious Influences on Environmental Concern and Activism." Journal for the Scientific Study of Religion 46(1):71-85.

Sherkat, Darren, Melissa Powell-Williams, Gregory Maddox, and Kylan Mattias de Vries. 2011. "Religion, Politics, and Support for Same-Sex Marriage in the United States, 1988-2008." Social Science Research 40(1):167-80.

Sherrill, Kenneth. 1996. “The Political Power of Lesbians, Gays, and Bisexuals.” PS: Political Science and Politics 29(3):469.

Sidanius, Jim and Felicia Pratto. 1999. Social Dominance: An Intergroup Theory of Social Hierarchy and Oppression. New York: Cambri. 
Simon, Rita. 1978. "Jews and Civil Liberties: American and Israeli Jewish Attitudes.” Judaism 27(1):33-39.

Smith, Tom. 1990. "Classifying Protestant Denominations." Review of Religious Research 31(3):225-45.

Smith, Tom. 2006. GSS Report: American Sexual Behavior. General Social Survey Topical Report No. 25. National Opinion Research Center, Chicago.

Smith, Tom, Jibum Kim, Achim Koch, and Alison Park. 2006. "Social-Science Research and the General Social Surveys.” Comparative Sociology 5(1):33-43.

Smith, Tom, Peter Marsden, Michael Hout, and Jibum Kim. 2015. General Social Surveys, 19722014 [Machine-Readable Data File]. Chicago, IL: National Opinion Research Center.

Sniderman, Paul and Thomas Piazza. 2002. Black Pride and Black Prejudice. Princeton, NJ: Princeton University Press.

Stacey, Judith and Barrie Thorne. 1985. "The Missing Feminist Revolution in Sociology.” Social Problems 32(4):301-16.

Strolovitch, Dara. 2008. Affirmative Advocacy: Race, Class, and Gender in Interest Group Politics. Chicago: Chicago University Press.

Stubager, Rune. 2008. "Education Effects on Authoritarian-Libertarian Values: A Question of Socialization.” British Journal of Sociology 59(2):327-50.

Sullivan, Andrew. 2005. "The End of Gay Culture: Assimilation and Its Meaning.” New Republic, October 24.

Tajfel, Henri. 1981. Human Groups and Social Categories. New York: Cambridge University Press.

Thornton, Arland and Linda Young-DeMarco. 2001. "Four Decades of Trends in Attitutdes toward Family Issues in the United States: The 1960s through the 1990s." Journal of Marriage and Family 63(4):1009-37.

Valelly, Richard. 2012. "LGBT Politics and American Political Development." Annual Review of Political Science 15(1):313-32.

Wedow, Robbee, Landon Schnabel, Lindsey Wedow, and Mary Ellen Konieczny. 2017. "'I'm Gay and I'm Catholic': Negotiating Two Complex Identities at a Catholic University." Sociology of Religion 78(3):289-317.

Worthen, Meredith, Susan Sharp, and Forrest Rodgers. 2012. "Gay and Lesbian Individuals' Attitudes Toward the Death Penalty: An Exploratory Study of the Roles of Empathic Concern and Political Beliefs." Criminal Justice Review 37(2):239-61.

Yip, Andrew and Sarah-Jan Page. 2013. Religious and Sexual Identities: A Multi-Faith Exploration of Young Adults. London: Ashgate. 


\section{FIGURES AND TABLES}

Figure 1: Articles on Gender, Race, and Sexuality in the American Sociological Review, American Journal of Sociology, and Social Forces

40

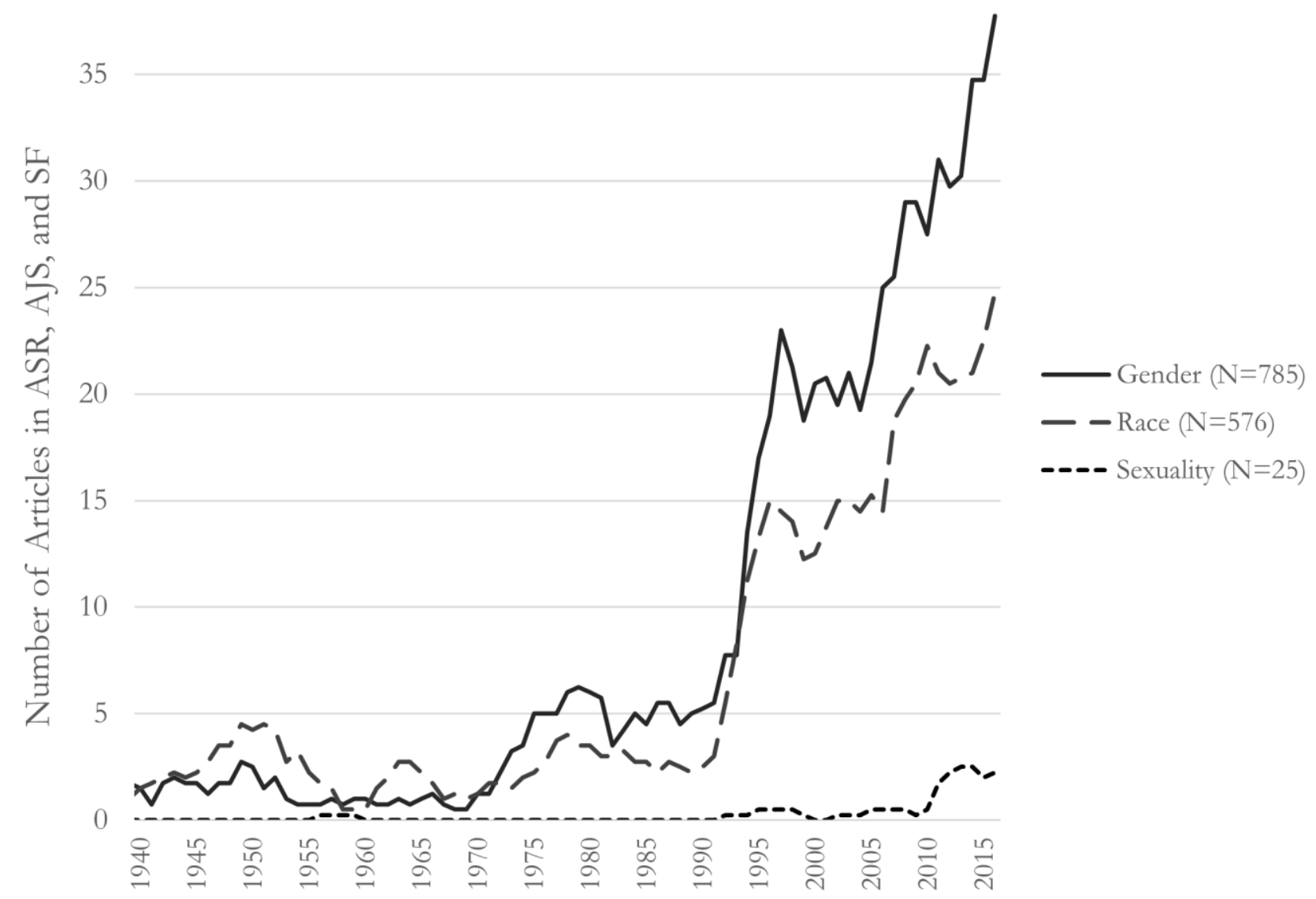

Calculated with Web of Science searches of articles in the American Sociological Review, American Journal of Sociology, and Social Forces with "Gender," "Race," and "Sexuality" as topics from 1936 (when ASR was founded) to 2016. Number of articles presented as four-year moving averages.

Note: "Sex" was used as the search term for "gender" through 1986 because it was the more common term until 1987 when gender overtook it (only one article was listed as on the topic of "gender" before 1980). I used single terms to search for gender (first using "sex," then "gender") and race, but used both "sexuality" and "sexual orientation" for sexuality to ensure I was not underestimating articles on the topic. I also searched and included hits using the terms "homosexuality" and "homosexual" prior to 1992 when the first hit for "sexuality" or "sexual orientation" occurred. 
Figure 2: Political Views by Sexual Identity and Sexual Behavior

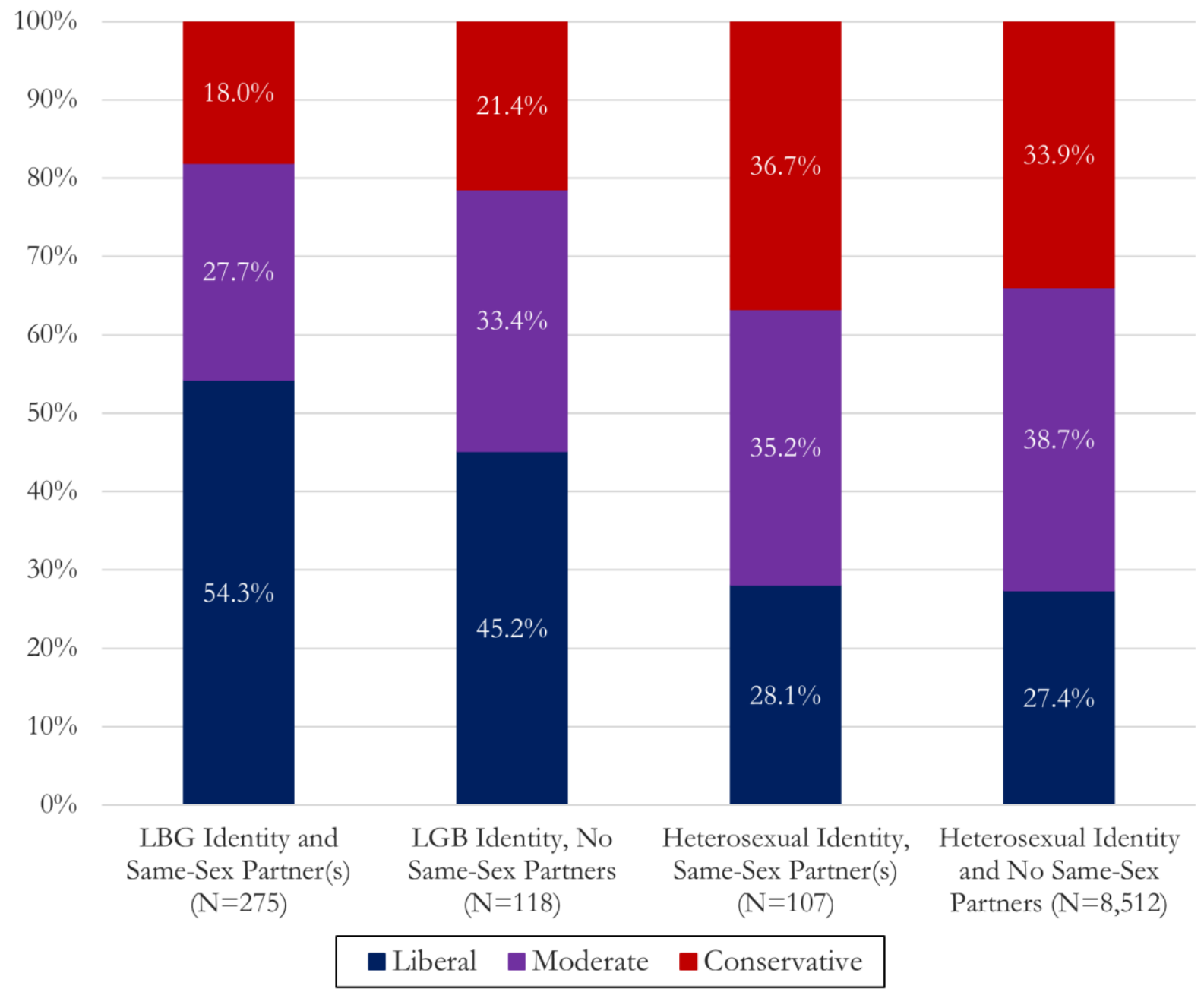

Source: General Social Survey, 2008-2016

Note: This figure presents post-estimation predictions of political views in three categories (liberal, moderate, and conservative) with covariates (gender, race/ethnicity, education, age, and survey year) held at global means. "No same-sex partners" includes those with no partnering information. 


\section{Figure 3: Sexual Behavior Predicting Political Self-Identification and Same-Sex Marriage} Views over Time

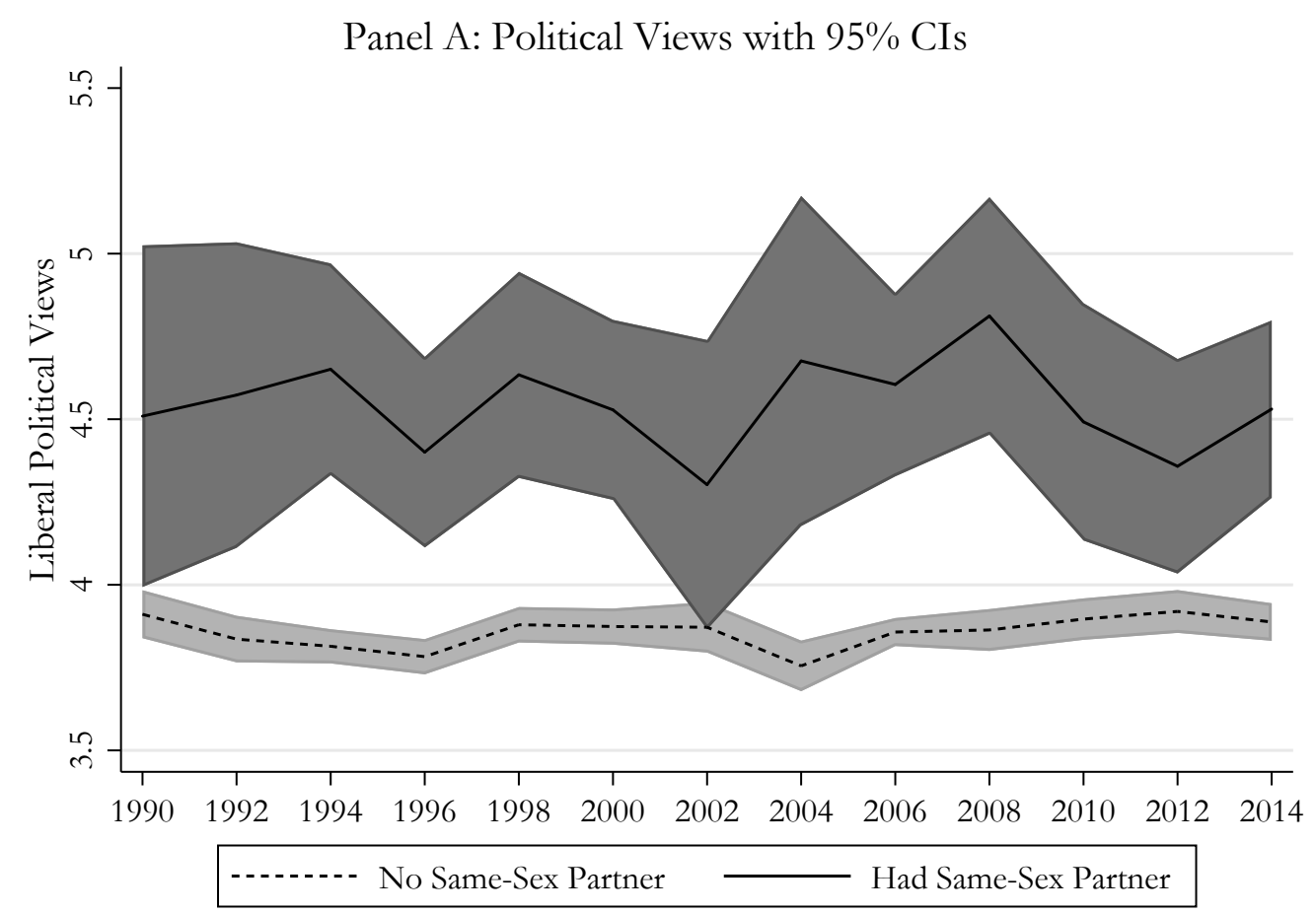

Panel B: Support for Same-Sex Marriage with 95\% CIs

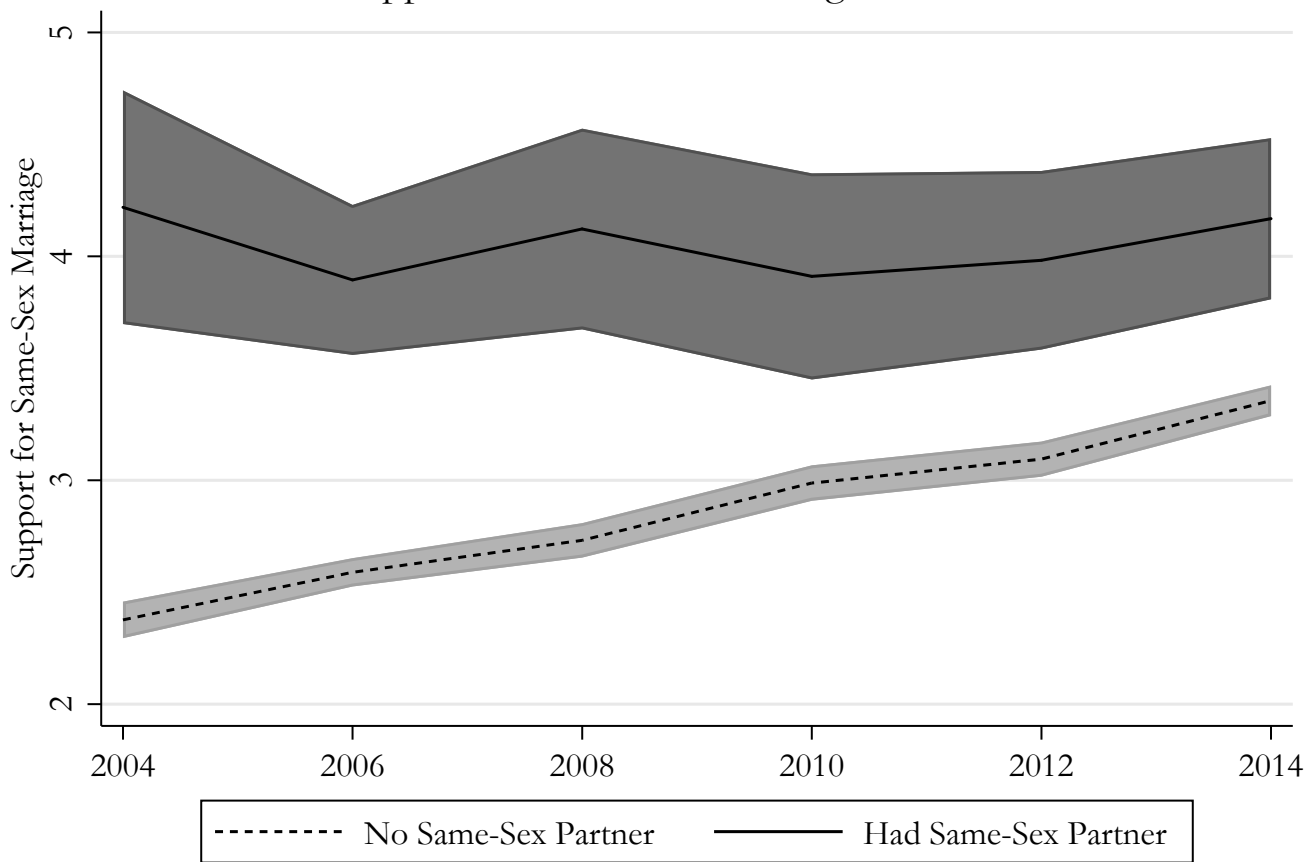

Note: Underlying models also included gender, race, education, and age. Political views measured from extremely conservative $=1$ to extremely liberal $=7$ and marriage views from strongly oppose $=1$ to strongly support $=5$. No samesex partners includes those with no partnering information (analyses separating them demonstrate equivalency). 
Figure 4: Summary of the Impact of Sexual Identity, Gender, Race, and Education on 101 Attitudinal Outcomes

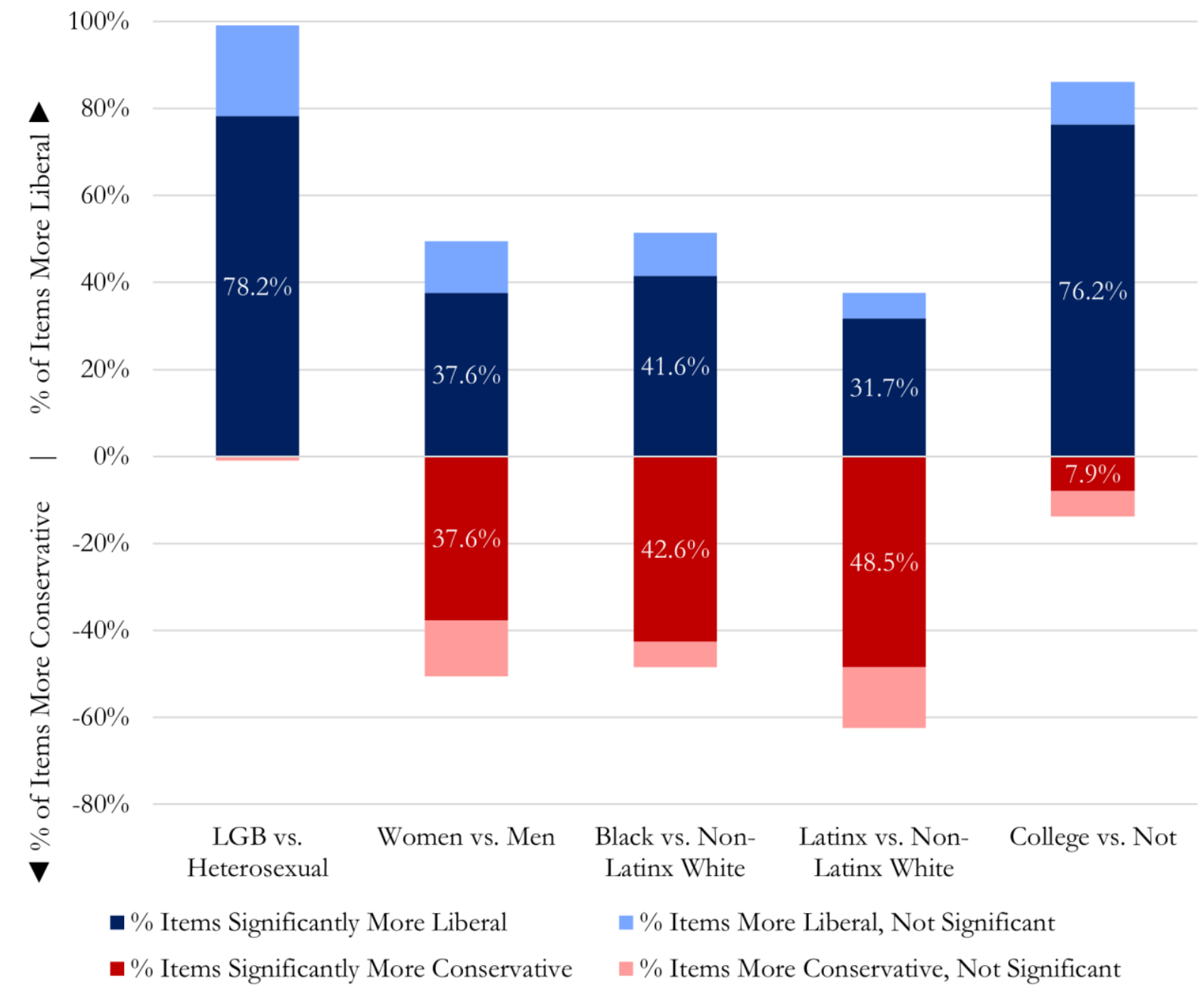

Source: General Social Survey, 2008-2016

Note: All models included sexual orientation, gender, race/ethnicity, education, age, and year. 
Table 1: Descriptions and Summary Statistics for Sexual Behavior and Identity, Sociodemographic Covariates, Religion, and General Political Views

\begin{tabular}{|c|c|c|c|}
\hline Measures & Metric & $\mathbf{N}$ & $\begin{array}{c}\text { Mean/ } \\
\text { Proportion } \\
\text { (SD) }\end{array}$ \\
\hline Sexual Behavior $^{\mathrm{a}}$ & & 9,321 & \\
\hline Heterosexual & Opposite-Sex Partners Only in Last Five Years & & .81 \\
\hline Sexual Minority & Had Same-Sex Partner in Last Five Years & & .04 \\
\hline No Partner Information & No Partner Information & & .15 \\
\hline Sexual Identity & Lesbian, Gay, or Bisexual Identity $=1$ & 9,321 & .04 \\
\hline Woman & Woman $=1$ & 9,321 & .55 \\
\hline Race/Ethnicity & & 9,321 & \\
\hline White & Non-Latinx White & & .69 \\
\hline Black & Non-Latinx Black & & .14 \\
\hline Latinx & Latinx & & .13 \\
\hline Other & Non-Latinx Other Race & & .04 \\
\hline College & Has College Degree $=1$ & 9,321 & .30 \\
\hline Religiosity & $\begin{array}{l}\text { 3-item Scale ( } a=.80 ; \text { Strength of Affiliation, } \\
\text { Attendance Frequency, and Prayer Frequency) }\end{array}$ & 9,321 & $\begin{array}{c}.00 \\
(1.00)\end{array}$ \\
\hline Affiliation Type & & 9,321 & \\
\hline None & No Religious Affiliation & & .20 \\
\hline Liberal & Liberal Religious Affiliation & & .12 \\
\hline Moderate & Moderate Religious Affiliation & & .39 \\
\hline Fundamentalist & Fundamentalist Religious Affiliation & & .24 \\
\hline Other/Missing & Affiliation Missing or Not in Scheme & & .04 \\
\hline General Political Views & Extremely Conservative $=1$, Extremely Liberal $=7$ & $9,012^{\mathrm{b}}$ & $\begin{array}{c}3.93 \\
(1.45)\end{array}$ \\
\hline
\end{tabular}

Source: General Social Survey, 2008-2016

${ }^{a}$ This measure was available from 1991-2016 and some analyses use older data as well $(\mathrm{N}=36,201)$.

${ }^{\mathrm{b}}$ Analyses that use political self-identification as a covariate employ imputation for missing data, allowing for an $\mathrm{N}$ of 9,321 with the same summary statistics as the unimputed measure (mean=3.93 and standard deviation $=1.45$ ). 
Table 2: Sexual Behavior and Sexual Identity Predicting Liberal Political Views

\begin{tabular}{|c|c|c|c|}
\hline & Model 1 & Model 2 & Model 3 \\
\hline \multicolumn{4}{|l|}{ Sexual Behavior } \\
\hline \multirow[t]{2}{*}{ Had Same-Sex Partner } & $0.60^{* * *}$ & & 0.07 \\
\hline & $(0.08)$ & & $(0.10)$ \\
\hline \multirow[t]{2}{*}{ No Partnering Information } & 0.01 & & -0.01 \\
\hline & $(0.04)$ & & $(0.04)$ \\
\hline \multicolumn{4}{|l|}{ Sexual Identity } \\
\hline \multirow{2}{*}{ LGB } & & $0.80^{* * *}$ & $0.75^{* * *}$ \\
\hline & & $(0.07)$ & $(0.10)$ \\
\hline \multicolumn{4}{|l|}{ Gender, Race, Education } \\
\hline \multirow[t]{2}{*}{ Woman } & $0.08^{* *}$ & $0.08^{* *}$ & $0.08^{* *}$ \\
\hline & $(0.03)$ & $(0.03)$ & $(0.03)$ \\
\hline \multirow[t]{2}{*}{ Black } & $0.29^{* * *}$ & $0.29^{* * *}$ & $0.29^{* * *}$ \\
\hline & $(0.04)$ & $(0.04)$ & $(0.04)$ \\
\hline \multirow[t]{2}{*}{ Latinx } & $0.13^{* *}$ & $0.13^{* *}$ & $0.13^{* *}$ \\
\hline & $(0.05)$ & $(0.05)$ & $(0.05)$ \\
\hline \multirow[t]{2}{*}{ Other Race } & $0.26^{* * *}$ & $0.27^{* * *}$ & $0.27^{* * *}$ \\
\hline & $(0.08)$ & $(0.08)$ & $(0.08)$ \\
\hline \multirow[t]{2}{*}{ College } & $0.28^{* * *}$ & $0.28^{* * * *}$ & $0.28^{* * *}$ \\
\hline & $(0.03)$ & $(0.03)$ & $(0.03)$ \\
\hline Constant & 4.07 & 4.05 & 4.05 \\
\hline$N$ & 9,012 & 9,012 & 9,012 \\
\hline$R^{2}$ & 0.03 & 0.04 & 0.04 \\
\hline
\end{tabular}

Standard errors in parentheses

Source: General Social Survey, 2008-2016

Note: These OLS models also include respondent age and a series of dichotomous measures for survey year.

${ }^{*} p<0.05,{ }^{* *} p<0.01,{ }^{* * *} p<0.001$ 
Table 3: Sexual Identity and Other Key Sociodemographic Factors Predicting Attitudes on Issues Closely Linked to Religious Values

\begin{tabular}{|c|c|c|c|c|c|c|c|c|c|}
\hline & \multicolumn{3}{|c|}{$\begin{array}{c}\text { Abortion Attitudes } \\
\text { Standardized Scale } \\
\text { (OLS Regression Coefficients) }\end{array}$} & \multicolumn{3}{|c|}{$\begin{array}{c}\text { Suicide Attitudes } \\
\text { Standardized Scale } \\
\text { (OLS Regression Coefficients) }\end{array}$} & \multicolumn{3}{|c|}{$\begin{array}{c}\text { Science Attitudes } \\
\text { Standardized Scale } \\
\text { (OLS Regression Coefficients) }\end{array}$} \\
\hline & Model 1 & Model 2 & Model 3 & Model 4 & Model 5 & Model 6 & Model 7 & Model 8 & Model 9 \\
\hline \multirow[t]{2}{*}{ LGB } & $0.36^{* * *}$ & $0.22^{* * *}$ & $0.14^{*}$ & $0.35^{* * *}$ & $0.26^{* * *}$ & $0.21^{* *}$ & $0.27^{* * *}$ & $0.18^{* *}$ & 0.12 \\
\hline & $(0.07)$ & $(0.06)$ & $(0.06)$ & $(0.07)$ & $(0.06)$ & $(0.06)$ & $(0.07)$ & $(0.07)$ & $(0.07)$ \\
\hline \multirow[t]{2}{*}{ Woman } & $-0.10^{* * *}$ & $0.05^{*}$ & 0.02 & $-0.18^{* * *}$ & $-0.08^{* *}$ & $-0.10^{* * *}$ & $-0.15^{* * *}$ & -0.05 & $-0.08^{* *}$ \\
\hline & $(0.03)$ & $(0.02)$ & $(0.02)$ & $(0.03)$ & $(0.03)$ & $(0.03)$ & $(0.03)$ & $(0.03)$ & $(0.03)$ \\
\hline \multirow[t]{2}{*}{ Black } & -0.07 & $0.24^{* * *}$ & $0.15^{\text {**** }}$ & $-0.33^{* * *}$ & $-0.17^{* * * *}$ & $-0.21^{* * * *}$ & $-0.18^{* * * *}$ & 0.01 & -0.05 \\
\hline & $(0.04)$ & $(0.04)$ & $(0.04)$ & $(0.04)$ & $(0.04)$ & $(0.04)$ & $(0.04)$ & $(0.04)$ & $(0.04)$ \\
\hline \multirow[t]{2}{*}{ Latinx } & $-0.32^{* * *}$ & $-0.21^{* * *}$ & $-0.24^{* * *}$ & $-0.31^{* * *}$ & $-0.23^{* * *}$ & $-0.25^{* * *}$ & 0.02 & 0.06 & 0.05 \\
\hline & $(0.04)$ & $(0.04)$ & $(0.04)$ & $(0.04)$ & $(0.04)$ & $(0.04)$ & $(0.05)$ & $(0.05)$ & $(0.05)$ \\
\hline \multirow[t]{2}{*}{ Other Race } & 0.08 & 0.02 & 0.01 & $-0.18^{* *}$ & $-0.22^{* *}$ & $-0.23^{* * *}$ & $0.28^{* * * *}$ & $0.24^{* * *}$ & $0.22^{* *}$ \\
\hline & $(0.06)$ & $(0.06)$ & $(0.06)$ & $(0.07)$ & $(0.07)$ & $(0.07)$ & $(0.07)$ & $(0.07)$ & $(0.07)$ \\
\hline \multirow[t]{2}{*}{ College } & $0.38^{* * *}$ & $0.34^{* * *}$ & $0.30^{* * *}$ & $0.33^{* * *}$ & $0.31^{* * *}$ & $0.30^{* * *}$ & $0.38^{* * *}$ & $0.34^{* * *}$ & $0.33^{* * *}$ \\
\hline & $(0.03)$ & $(0.03)$ & $(0.03)$ & $(0.03)$ & $(0.03)$ & $(0.03)$ & $(0.03)$ & $(0.03)$ & $(0.03)$ \\
\hline Religion & No & Yes & Yes & No & Yes & Yes & No & Yes & Yes \\
\hline Political Views & No & No & Yes & No & No & Yes & No & No & Yes \\
\hline Constant & 0.05 & -0.43 & -1.04 & 0.35 & 0.26 & 0.02 & 0.16 & -0.01 & -0.37 \\
\hline$N$ & 5,865 & 5,865 & 5,865 & 5,882 & 5,882 & 5,882 & 4,483 & 4,483 & 4,483 \\
\hline$R^{2}$ & 0.06 & 0.24 & 0.28 & 0.06 & 0.13 & 0.14 & 0.06 & 0.14 & 0.15 \\
\hline
\end{tabular}

Standard errors in parentheses

Source: General Social Survey, 2008-2016

Note: Higher coefficients indicate more liberal scores on the scales. "Religion" includes a religiousness scale (strength of affiliation, attendance frequency, and prayer frequency) and a categorical measure of fundamentalism of affiliation. "Political views" is self-placement on a scale from extremely conservative $=1$ to extremely liberal $=7$. All models also include respondent age and a series of dichotomous measures for survey year. ${ }^{*} p<0.05,{ }^{* *} p<0.01,{ }^{* * * *} p<0.001$ 
Table 4: Sexual Identity and Other Key Sociodemographic Factors Predicting Attitudes toward Key Contemporary Issues

\begin{tabular}{|c|c|c|c|c|c|c|c|c|c|}
\hline & \multicolumn{3}{|c|}{$\begin{array}{c}\text { Race Attitudes } \\
\text { Standardized Scale } \\
\text { (OLS Regression Coefficients) }\end{array}$} & \multicolumn{3}{|c|}{$\begin{array}{c}\text { Free Speech Attitudes } \\
\text { Standardized Scale } \\
\text { (OLS Regression Coefficients) } \\
\end{array}$} & \multicolumn{3}{|c|}{$\begin{array}{l}\text { Support Marijuana Legalization } \\
\text { (Logistic Regression Odds Ratios) }\end{array}$} \\
\hline & Model 1 & Model 2 & Model 3 & Model 4 & Model 5 & Model 6 & Model 7 & Model 8 & Model 9 \\
\hline \multirow[t]{2}{*}{ LGB } & $0.29^{* * *}$ & $0.24^{* * *}$ & $0.15^{* * *}$ & $0.26^{* * *}$ & $0.19^{* * *}$ & $0.17^{* *}$ & $3.44^{* * *}$ & $2.85^{* * *}$ & $2.48^{* * *}$ \\
\hline & $(0.04)$ & $(0.04)$ & $(0.04)$ & $(0.06)$ & $(0.06)$ & $(0.06)$ & $(0.53)$ & $(0.45)$ & $(0.40)$ \\
\hline \multirow[t]{2}{*}{ Woman } & $0.10^{\text {**** }}$ & $0.13^{* * * *}$ & $0.09^{* * * *}$ & $-0.12^{* * * *}$ & $-0.05^{*}$ & $-0.06^{* *}$ & $0.67^{* * *}$ & $0.82^{* * *}$ & $0.77^{* * * *}$ \\
\hline & $(0.02)$ & $(0.02)$ & $(0.02)$ & $(0.02)$ & $(0.02)$ & $(0.02)$ & $(0.04)$ & $(0.05)$ & $(0.04)$ \\
\hline \multirow[t]{2}{*}{ Black } & $0.83^{* * *}$ & $0.88^{* * *}$ & $0.79^{* * * *}$ & $-0.38^{\text {*** }}$ & $-0.22^{* * * *}$ & $-0.25^{* * *}$ & 0.92 & $1.32^{* * * *}$ & 1.13 \\
\hline & $(0.03)$ & $(0.03)$ & $(0.03)$ & $(0.03)$ & $(0.03)$ & $(0.03)$ & $(0.07)$ & $(0.11)$ & $(0.10)$ \\
\hline \multirow[t]{2}{*}{ Latin $x$} & $0.13^{* * * *}$ & $0.16^{* * * *}$ & $0.12^{* * * *}$ & $-0.37^{* * *}$ & $-0.36^{* * * *}$ & $-0.37^{* * * *}$ & $0.42^{* * *}$ & $0.45^{* * *}$ & $-0.41^{* * * *}$ \\
\hline & $(0.03)$ & $(0.03)$ & $(0.03)$ & $(0.04)$ & $(0.04)$ & $(0.04)$ & $(0.04)$ & $(0.04)$ & $(0.04)$ \\
\hline \multirow[t]{2}{*}{ Other Race } & $0.12^{* *}$ & 0.08 & 0.05 & $-0.33^{* * *}$ & $-0.38^{* * *}$ & $-0.38^{* * *}$ & $0.61^{* * *}$ & $0.57^{* * *}$ & $0.52^{* * *}$ \\
\hline & $(0.04)$ & $(0.04)$ & $(0.04)$ & $(0.06)$ & $(0.05)$ & $(0.05)$ & $(0.08)$ & $(0.08)$ & $(0.07)$ \\
\hline \multirow[t]{2}{*}{ College } & $0.34^{* * *}$ & $0.31^{* * * *}$ & $0.28^{* * * *}$ & $0.58^{* * *}$ & $0.55^{\text {**** }}$ & $0.53^{* * *}$ & 1.11 & 1.08 & 1.02 \\
\hline & $(0.02)$ & $(0.02)$ & $(0.02)$ & $(0.02)$ & $(0.02)$ & $(0.02)$ & $(0.07)$ & $(0.066)$ & $(0.06)$ \\
\hline Religion & No & Yes & Yes & No & Yes & Yes & No & Yes & Yes \\
\hline Political Views & No & No & Yes & No & No & Yes & No & No & Yes \\
\hline Constant & -0.08 & 0.04 & -0.53 & 0.44 & 0.36 & 0.17 & 2.29 & 1.70 & 0.59 \\
\hline$N$ & 9,319 & 9,319 & 9,319 & 5,904 & 5,904 & 5,904 & 6,377 & 6,377 & 6,377 \\
\hline$R^{2} / M c F a d d e n$ 's $R^{2}$ & 0.15 & 0.17 & 0.22 & 0.15 & 0.20 & 0.20 & 0.06 & 0.11 & 0.14 \\
\hline
\end{tabular}

Standard errors in parentheses

Source: General Social Survey, 2008-2016

Note: Higher coefficients indicate more liberal scores on the standardized scales. "Religion" includes a religiousness scale (strength of affiliation, attendance frequency, and prayer frequency) and a categorical measure of fundamentalism of affiliation. "Political views" is self-placement on a scale from extremely conservative $=1$ to extremely liberal $=7$. All models also include respondent age and a series of dichotomous measures for survey year. ${ }^{*} p<0.05,{ }^{* *} p<0.01,{ }^{* * *} p<0.001$ 
Table 5: Sexual Identity and Other Key Sociodemographic Characteristics Predicting Standardized Attitude Scales on Eight Additional General Topics Covered by the General Social Survey

\begin{tabular}{|c|c|c|c|c|c|c|c|c|}
\hline & $\begin{array}{c}\text { Political } \\
\text { Affiliation } \\
\text { and Views }\end{array}$ & Sexuality & $\begin{array}{c}\text { Gender and } \\
\text { Family }\end{array}$ & $\begin{array}{c}\text { Economy \& } \\
\text { Role of } \\
\text { Government }\end{array}$ & $\begin{array}{l}\text { Crime and } \\
\text { Discipline }\end{array}$ & $\begin{array}{c}\text { Immigration } \\
\& \\
\text { Nationalism } \\
\end{array}$ & $\begin{array}{l}\text { Confidence } \\
\text { in } \\
\text { Institutions } \\
\end{array}$ & $\begin{array}{c}\text { Religion and } \\
\text { Morality }\end{array}$ \\
\hline \multirow[t]{2}{*}{ LGB } & $0.54^{* * *}$ & $0.55^{* * *}$ & $0.20^{* * * *}$ & $0.31^{* * *}$ & $0.23^{* * *}$ & $0.23^{* * *}$ & $0.33^{* * *}$ & $0.44^{* * * *}$ \\
\hline & $(0.05)$ & $(0.05)$ & $(0.06)$ & $(0.05)$ & $(0.05)$ & $(0.06)$ & $(0.06)$ & $(0.05)$ \\
\hline \multirow[t]{2}{*}{ Woman } & $0.10^{* * * *}$ & $-0.12^{* * *}$ & $0.28^{* * * *}$ & $0.06^{* *}$ & $0.13^{* * *}$ & $0.11^{* * *}$ & -0.01 & $-0.30^{* * * *}$ \\
\hline & $(0.02)$ & $(0.02)$ & $(0.02)$ & $(0.02)$ & $(0.02)$ & $(0.02)$ & $(0.03)$ & $(0.02)$ \\
\hline \multirow[t]{2}{*}{ Black } & $0.59^{* * * *}$ & $-0.10^{* * * *}$ & -0.03 & $0.50^{* * *}$ & $0.52^{* * *}$ & $0.24^{* * * *}$ & $0.24^{* * *}$ & $-0.57^{* * *}$ \\
\hline & $(0.03)$ & $(0.03)$ & $(0.03)$ & $(0.03)$ & $(0.03)$ & $(0.03)$ & $(0.04)$ & $(0.03)$ \\
\hline \multirow[t]{2}{*}{ Latinx } & $0.29^{* * *}$ & $-0.19^{* * *}$ & $-0.34^{* * *}$ & $0.11^{* * * *}$ & $0.44^{* * *}$ & $0.38^{* * *}$ & $0.34^{* * *}$ & $-0.35^{\text {**** }}$ \\
\hline & $(0.03)$ & $(0.03)$ & $(0.04)$ & $(0.03)$ & $(0.03)$ & $(0.04)$ & $(0.04)$ & $(0.03)$ \\
\hline \multirow[t]{2}{*}{ Other Race } & $0.31^{* * *}$ & 0.03 & $-0.36^{* * *}$ & $0.17^{* * *}$ & $0.22^{* * *}$ & $0.35^{* * *}$ & $0.36^{* * *}$ & -0.04 \\
\hline & $(0.05)$ & $(0.05)$ & $(0.06)$ & $(0.05)$ & $(0.05)$ & $(0.06)$ & $(0.06)$ & $(0.05)$ \\
\hline \multirow[t]{2}{*}{ College } & $0.16^{* * *}$ & $0.31^{* * *}$ & $0.38^{* * *}$ & $0.08^{* * *}$ & $0.24^{* * *}$ & $0.26^{* * *}$ & $0.12^{* * *}$ & $0.40^{* * * *}$ \\
\hline & $(0.02)$ & $(0.02)$ & $(0.03)$ & $(0.02)$ & $(0.02)$ & $(0.03)$ & $(0.03)$ & $(0.02)$ \\
\hline Constant & -0.07 & 0.50 & 0.25 & $0.13^{* * *}$ & -0.11 & 0.00 & 0.14 & 0.60 \\
\hline$N$ & 9,305 & 9,319 & 5,901 & 9,320 & 9,312 & 7,792 & 6,830 & 9,311 \\
\hline$R^{2}$ & 0.07 & 0.08 & 0.11 & 0.05 & 0.06 & 0.06 & 0.05 & 0.12 \\
\hline
\end{tabular}

Standard errors in parentheses

Source: General Social Survey, 2008-2016

${ }^{*} p<0.05,{ }^{* *} p<0.01,{ }^{* * *} p<0.001$

Note: These OLS models also include age and dichotomous measures for survey year (not shown). Higher coefficients indicate more liberal scores on the scales. 